\title{
Mammary Tuberculosis - A Case Report
}

\author{
Surg Lt Cdr A Chauhan*, Lt Col S Kakkar ${ }^{+}$, Air Cmde S Mahapatra\#, vsM
}

MJAFI 2006; 62 : 385-386

Key Words: Mammary tuberculosis

\section{Introduction}

$\mathrm{T}$ uberculosis of breast is an extremely rare disease. The breast tissue is remarkably resistant to tuberculosis, as are skeletal muscle and spleen [1]. Only few cases have been reported from the Indian subcontinent in spite of the high prevalence of tuberculosis in this region [2] and 500 cases of mammary tuberculosis have been documented worldwide [3]. Without well-defined clinical features, the true nature of the disease remains obscure and it is often mistaken for carcinoma or pyogenic inflammatory disease of the breast $[4,5]$. We present a case of primary tuberculosis of breast which presented as acute pyogenic abcess for which the patient underwent repeated incision and drainage.

\section{Case report}

A 32 year old married female, gravida 2 in 28 weeks of gestation, presented with progressively increasing, painful lump in left breast of one week duration and associated low grade evening fever. There was no history of any discharge from either nipple. On examination, she had a tender, firm, ill defined, lump in the left outer quadrant of breast measuring $7 \times 5 \mathrm{~cm}$. Overlying skin was erythematous and indurated but there was no evidence of fixity to the skin or the underlying tissues. The nipple and areola were normal. Opposite breast was normal. There was no axillary or cervical lymphadenopathy. The chest examination was normal. Examination of the abdomen revealed no evidence of any intra abdominal lump or ascites. Haemoglobin was $10 \mathrm{gm} \%$, white blood count was 9,800 with polymorphs $54 \%$, lymphocytes $42 \%$, eosinophils $4 \%$. Erythrocyte sedimentation rate was $40 \mathrm{~mm}$ at end of one hour by Westergren method. Liver function tests were normal. Radiograph of chest was normal. Needle aspiration revealed purulent material. She was clinically diagnosed to be a case of acute breast abcess (right). Incision and drainage ( I \& D) was done. Peroperatively, there was a large pus filled cavity from which approximately $30 \mathrm{cc}$ of pus was drained. Dependant drainage was established by corrugated rubber drain. Post operatively, she was put on inj cloxacillin $500 \mathrm{mg}$ six hourly and inj gentamicin $60 \mathrm{mg}$ eight hourly. Patient was discharged after five days once drainage stopped. She reported again in OPD within five days with recurrence of abcess. She was taken up for repeat I \& D. Peroperatively another abcess cavity in close proximity to and in communication with original cavity was found. Pus was evacuated and dependant drainage re established. Patient was discharged on seventh post operative day. She presented for the third time with recurrence of abcess and persistent discharge from the site of previous incisions. I \& D was done for third time and a biopsy was taken from the wall of the abcess cavity. Histopathological examination revealed tuberculous granulomas consisting of caseation, epitheloid cells and Langhan's giant cells hence confirming the diagnosis of tuberculosis of breast (Fig 1). Sputum for acid fast bacilli, done on three separate occasions, was negative. Repeat chest radiograph did not reveal any pulmonary foci of tuberculosis. Polymearse chain reaction (PCR) for mycobacterium tuberculosis was positive. The patient was put on ethambutol, INH, rifampicin and pyrazinamide (EHRZ) antitubercular therapy (ATT) regime. Presently she is on fortnightly followup. She has completed five months of the ATT course. The sinus tracts have healed

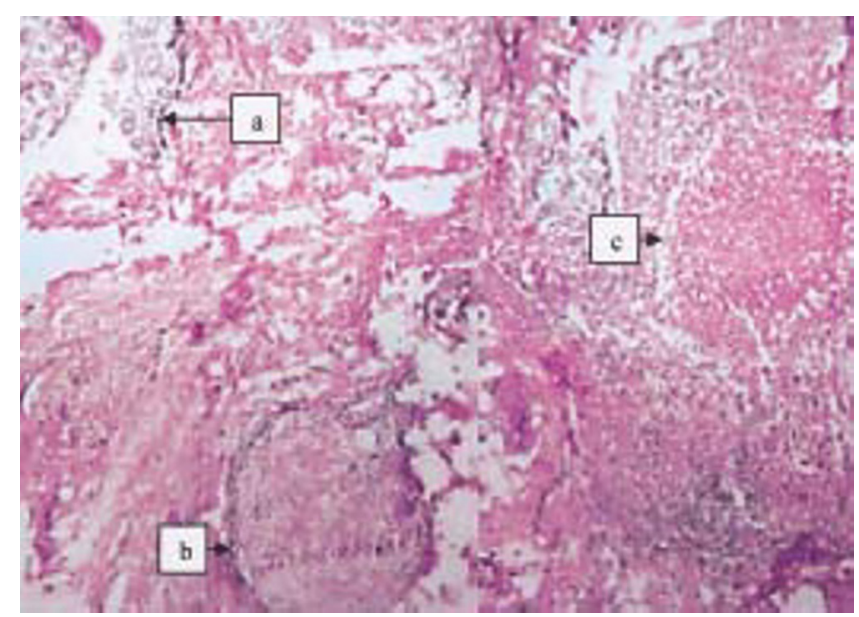

Fig. 1 : Histopath examination of biopsy from wall of abscess (a) normal breast tissue (b) granuloma with epitheloid cells (c) foci of caseation

${ }^{*}$ Graded Specialist (Surgery), Base Hospital, Delhi Cantt. ${ }^{+}$Classified Specialist (Oncopathology), Base Hospital, Delhi Cantt. "PMO, Southern Air Command, Trivandrum. 
and areas of induration resolved. However, a $3 \times 2 \mathrm{~cm}$ area of residual, tender lumpiness persists in upper outer quadrant of the affected breast. Her pregnancy is progressing well without any complications

\section{Discussion}

The tuberculosis of breast is a disease of younger age group. Uncommonly an older patient may present with a mass that mimics carcinoma, whereas the younger patient usually manifest signs of a pyogenic breast abscess $[2,4]$. Our case presented with typical history and clinical features suggestive of acute pyogenic abscess. Breast tuberculosis may be primary where the breast lesion is the only manifestation of the disease or it may be secondary in which a focus of tuberculosis has already been diagnosed elsewhere in the body and the disease appears in the breast at a later stage. There are three recognised modes of spread of the tubercle bacilli to the breast namely; direct, lymphatic and haematogenous. Rarely, infected sputum can reach the underlying breast through superficial abrasions of the skin of the breast. In all cases bacilli infect the ducts and spare the lobules. Dilated ducts of the breast in pregnant and lactating women appear to be especially susceptible to infection $[4,6]$. Tuberculosis of breast has been classified into five different types: acute miliary tuberculosis mastitis, nodular tuberculosis mastitis, disseminated tuberculosis mastitis, sclerosing tuberculosis mastitis and tuberculosis mastitis obliterans [7]. Early diagnosis is difficult, as the characteristic sinuses occur late in the course of the disease. In addition, presence of these sinuses is not the distinctive feature of tuberculosis, as several cases of non-tuberculosis granulomatous mastitis also present with sinuses. However, tuberculosis should be suspected in a patient with a recurring breast abscess inspite of adequate drainage and antibiotic therapy on previous occasions. Multiple biopsies and histopathological examination is imperative to establish diagnosis [7]. Though previous reports suggest that demonstration of AFB is a must, a recent study refutes this statement. In a cytomorphology study of 160 cases of breast tuberculosis, authors opine that in a combination of epitheloid cell granulomas and caseous necrosis, a diagnosis of breast tuberculosis can be given and determination of AFB positivity is not a must [8]. The diagnosis in our case was clinched by the presence of granulomatous infiltrates and tubercles with central caseation, seen on histology though bacteriological culture of the aspirate was negative for mycobacterium tuberculosis.

Successful treatment combines antituberculous drug therapy with removal of residual infected breast tissue $[1,7]$. EHRZ therapy to expecting mother does not have deleterious effect on foetus though use of inj streptomycin is contraindicated as it may result in congenital deafness [9]. Our patient responded well to ATT and her pregnancy proceeds uneventfully. In conclusion, it would be prudent to suggest that though rare, tuberculous mastitis should be kept in mind when dealing with recurrent breast abscess especially in pregnant or lactating ladies.

\section{Conflicts of Interest}

None identified

\section{References}

1. Azzopardi JG. Problems in Breast Pathology. In: JL Bennington, editor. Major problems in pathology. $1^{\text {st }}$ ed. Philadelphia: WB Saunders, 1979; 399-400.

2. Sharma AK, Sree S, Misra SK. Tuberculosis mastitis: a pragmatic approach to its management. Aust NZJ Surg 1993; 63: 263-5.

3. Hale JA, Peters GN, Cheek JH. Tuberculosis of the Breast: rare but still extant. Review of the literature and report of an additional case. Am J Surg 1985; 150: 620-4.

4. Alagaratnam TT, Ong GB. Tuberculosis of the breast. Brit J Surg 1980; 67: 125-6.

5. Shinde SR, Chandawarkar RY, Deshmukh SP. Tuberculosis of the breast masquerading as carcinoma: a study of 100 patients. World J Surg. 1995; 19: 379-81.

6. Mckeown KC, Wilkinson KW. Tuberculous disease of the breast. Brit J Surg 1992; 39: 420-9.

7. Sharma PK, Babel AL, Yadav SS. Tuberculosis of breast (study of seven cases). J Postgrad Med 1991; 37: 24-6.

8. Kakkar S, Kapila K, Singh MK. Tuberculosis of the Breast. A cytomorphological study. Acta Cytol 2000; 44: 292-6.

9. Stoll BJ, Kliegman R. Maternal Disease and foetus. In: Richard Behrman, Robert Kliegman, editors. Nelson Textbook of Paediatrics. $16^{\text {th }}$ ed. Philadelphia: WB Saunders, 2000; 467-8. 